\title{
MiR-144 Regulates Hemoglobin Expression in Human Erythroid Cell Line $^{\dagger}$
}

\section{Tipparat PENGLONG ${ }^{1}$, Apisara SAENSUWANNA ${ }^{2}$ Jitpanu KOCHAROENWAT ${ }^{3}$, Wittawat BOORINTARAGOT ${ }^{3}$, Suppanut FUPONGSIRIPHAN ${ }^{3}$ and Kanitta SRINOUN ${ }^{3, *}$}

\author{
${ }^{I}$ Department of Pathology, Faculty of Medicine, Prince of Songkla University, Songkhla 90110, Thailand \\ ${ }^{2}$ Department of Biomedical Sciences, Faculty of Medicine, Prince of Songkla University, \\ Songkhla 90110, Thailand \\ ${ }^{3}$ Faculty of Medical Technology, Prince of Songkla University, Songkhla 90110, Thailand
}

('Corresponding author's e-mail: kanitta.s@psu.ac.th)

Received: 23 April 2019, Revised: 15 July 2019, Accepted: 19 August 2019

\begin{abstract}
The regulation of globin gene expression is significantly important to understand the pathogenesis of globin gene disorders. Recent findings have shown that microRNAs (miRNAs, miRs) play an important role in the regulation of globin gene expression. The miR-144 is an erythroid lineage-specific miRNA, in which its expression mediates NRF2 gene silencing and inhibits fetal hemoglobin expression. However, roles of miR-144 to other globin genes expression especially in a-globin cluster remain unknown. This study, thus, examined the functional studies of miR-144 to globin gene expression in K562 human erythroid cell line. The results revealed that a-globin and $\zeta$-globin gene expression were silenced by the overexpressed miR-144 and that correlated with the reduced expression of KLF1- the suspected target gene. By contrast, transfection with miR-144 inhibitor reversed the silencing effect of miR-144. On the other hand, miR-144 had no effect to $\beta$-globin gene expression. Our results sustain the findings of the previous studies that the overexpression of miR-144 correlates with the repressing of $N R F 2$ and $\boldsymbol{\gamma}$-globin gene expression. Taken together, our results suggest that miR-144 plays a key role in globin gene expression by silencing $\boldsymbol{\gamma}$-globin through $N R F 2$ target mRNA and repressing adult $a$-globin and embryonic $\zeta$-globin gene expression possibly by targeting KLF1 gene.
\end{abstract}

Keywords: MiR-144, $\boldsymbol{\gamma}$-globin, a-globin, $\zeta$-globin

\footnotetext{
${ }^{\dagger}$ Presented at the International Conferences on Biomedical Sciences and Medical Technology 2019: June 20 - 21, 2019
} 


\section{Introduction}

In human, a-globin cluster comprises of $\zeta, a 1$ and $a 2$ which developmentally express during primitive erythropoiesis in yolk sac ( $\zeta$-globin) and adult erythropoiesis in bone marrow (a1- and a2globin) [1]. The $\beta$-globin cluster contains 5 genes that are differentially regulated; $\varepsilon$-globin expresses in yolk sac, ${ }^{\mathrm{G}} \boldsymbol{\gamma}$ - and ${ }^{\mathrm{A}} \boldsymbol{\gamma}$-globin express in fetal liver, and $\delta$ - and $\beta$-globin express in bone marrow [2]. Studying the regulation of globin gene expression may give essential information on molecular mechanism underlying the pathogenesis of genetic hematological disease, such as sickle cell disease (SCD) and thalassemia [3,4].

Trans-acting elements including erythroid specific and general transcriptional regulators such as EKLF, GATA-1, and FOG-1 play an vital role in regulating the expression of globin genes [4,5]. Erythroid Kruppel-like factor (EKLF) or Kruppel-like factor $1(K L F 1)$ is a transcription factor regulating $\gamma$ - and $\beta$-globin gene expression. KLF1 controls globin gene switching by directly interacting with the CACCC boxes of $\beta$-globin promotor to activate $\beta$-globin expression and up-regulates BCL11A, a known repressor of $\gamma$-globin expression. [5-9]. Nuclear factor-like 2 (NRF2) is a transcription factor that regulates the expression of antioxidant proteins. It is bound with the $\gamma$-globin antioxidant response element, which can be inhibited by miR-144 mimic. The previous study showed that a miR-144/NRF2 had regulated the expression of $\gamma$-globin gene in SCD [10]. Although these advanced knowledges are well established in $\beta$-globin cluster, little is known about trans-acting elements regulating a-globin cluster.

MicroRNAs are endogenous small non-coding linear RNAs, approximately 20 nucleotides that regulate gene expression at the posttranscriptional level by targeting mRNAs for cleavage or translational repression [11]. Accumulating evidence indicates that miRNAs play a critical role in globin gene regulation. The expression of many miRNAs is correlated with the alteration of HbF synthesis. The miR96 is associated with the silencing of $\boldsymbol{\gamma}$-globin expression [12], whereas LIN28B is repressed by let-7 miRNA caused decreased expression of BCL11A as a mechanism of HbF induction [13]. Increased miR15a and miR-16-1 expression in human erythroid cell is correlated with the increasing of fetal and embryonic $\mathrm{Hb}$ gene expression by downregulating MYB [14]. Similarly, miR-486-3p controls $\boldsymbol{\gamma}$-globin expression by directly modulating BCL11A [15]. The miR-34a activates $\boldsymbol{\gamma}$-globin expression in K562 cell line through STAT3 gene silencing [16]. The overexpressed miR-326 in K562 and CD34 ${ }^{+}$hematopoietic progenitor cells regulates $\mathrm{HbF}$ synthesis by targeting EKLF mRNA [17]. Recently, the study in CD34 hematopoietic progenitor cells of sickle cell disease and KU812 cell line has demonstrated that miR-144 mediates $N R F 2$ gene silencing and inhibits fetal hemoglobin expression [10]. The first evidence revealed that the regulation of a-globin gene expression by miRNA was demonstrated in zebrafish model. This study also displayed that miR-144 was expressed at specific development stages and negatively regulated embryonic a-globin (a-E1) through Kruppel-like factor D (klfd) target gene [18]. However, roles of miR144 to a-globin cluster of human erythropoiesis remains unknown.

In this study, the function of miR-144 in the regulation of globin gene expression through its target mRNA; NRF2 and KLF1 were investigated.

\section{Materials and methods}

\section{Cell culture}

K562 cells, a chronic myelogenous leukemia-derived cell line, were cultured in RPMI 1640 medium with $10 \%$ heat-inactivated fetal bovine serum (FBS, GIBCO-Invitrogen, NY, USA), $2 \mathrm{~mm}^{3}$ glutamine, and antibiotics under $5 \% \mathrm{CO}_{2}, 37^{\circ} \mathrm{C}$ condition.

\section{miR-144 mimic and anti-miR-144 inhibitor transfection}

To study the effects of miR-144, gain and loss were performed. $2 \times 10^{5} \mathrm{~K} 562$ cells $/$ well with $40 \mathrm{~nm}$ hsa-miR-144 miRNA mimic and negative mimic control (mirVana ${ }^{\mathrm{TM}}$ miRNA mimic; Applied Biosystem, Foster City, CA, USA) was used to increase miRNA expression. MiR-144 inhibitor with $400 \mathrm{~nm}$ and negative miRNA inhibitor (Anti-miR ${ }^{\mathrm{TM}}$ miRNA Inhibitor; Applied Biosystem) was used for decrease miRNA expression. MiRNA mimic and inhibitor were transfected to K562 cell using RNAiMAX 
http://wjst.wu.ac.th

(Invitrogen). Cells were harvested at $72 \mathrm{~h}$ after transfection. The expression of miR-144, its target and globin genes were examined by qRT-PCR.

\section{miRNA and target gene expression}

Total RNAs were extracted from transfected K562 cell line using the Hybrid-R ${ }^{\mathrm{TM}}$ miRNA Isolation Kit (GeneAll, Seoul, South Korea) according to the manufacturer's instructions. The concentration of RNA was detected with a NanoDrop 2000 Spectrophotometer (Thermo Scientific, DE, USA). Mature miRNAs expression specific for miR-144 was evaluated by TaqMan ${ }^{\circledR}$ Small RNA Assays (Applied Biosystems) and using RNU48 as a reference gene. Briefly, total RNA was reversely transcribed using the specific looped primer, then reverse transcription quantitative PCR was conducted using the Taqman miRNA assay protocol. Amplification of miRNA by qRT-PCR was measured by LightCycler® 480 PCR System (Roche Molecular System, CA, USA). The experiments were carried out in triplicate. The expression of miRNA normalized on reference gene was calculated using $2^{-\Delta \Delta \mathrm{Ct}}$ (comparative $\mathrm{Ct}$ ) method.

To determine the levels of gene expression including nuclear factor-erythroid 2-related factor 2 (NRF2), KLF1, $\beta$-globin, $\boldsymbol{\gamma}$-globin, a-globin and $\zeta$-globin were analyzed by qRT-PCR. Total RNAs extracted from reticulocyte portion and K562 cell line were subjected to reverse transcription to complementary DNA (cDNA) using a High-Capacity RNA-to-cDNA kit (Applied Biosystems) according to established protocols. The amplification of cDNAs by the qRT-PCR method was done using SYBR Premix EX Taq TM (Takara Bio, Shiga, Japan) with specific primers, NRF2: forward primer, 5'GACGGTATG CAACAGGACATTGAG-'3, reverse primer, 5'- AACTTCTGTCAGTTTGGCTT CTGGA-3', GATA-1: forward primer 5'- CCCAAGAAGCGCCT GATTGT-3', reverse primer, 5'GTGTAGCTTGTAGTAGAGGCCGC-3', KLF1 or EKLF: forward primer 5'TTGCGGCAAGAGCTACACC-3', reverse primer 5'- CAGGCGTATGGCTTCTCCC-3', $\beta$-globin: forward primer 5'- TAACAG CATCAGGAGTGGACAGA-3', reverse primer 5'GCAAGGTGAACGTG GATGAAG-3', $\boldsymbol{\gamma}$-globin: forward primer 5'-GGCAACCTGTCCTCTGCCTC3', reverse primer 5' GAAATGGATTGCCAAAACGG-3', a-globin: forward primer 5'GCCCTGGAGAGGATGTTC- 3', reverse primer 5'-AGGGTCACCAGCAGGCAGT 3', $\zeta$-globin: forward primer 5'- GCCACCCGCAGACCAAGACC-3', reverse primer 5'AGGCGTGCAGCTCGCTCAG-3' and GAPDH: forward primer, 5'- GAAGGTGAAGGTCGGAGTC3', reverse primer, 5'- GAAGATGGTGATGGG ATTTC-3'. Amplification was performed with an initial denaturation at $95{ }^{\circ} \mathrm{C}$ for $30 \mathrm{~s}$. followed by 40 cycles of denaturation at $95{ }^{\circ} \mathrm{C}$ for $3 \mathrm{~s}$., annealing at $60^{\circ} \mathrm{C}$ for $30 \mathrm{~s}$, and melt curve stage. GAPDH served as the internal control. Normalized values $\left(2^{-\Delta \Delta \mathrm{Ct}}\right)$ were compared among samples and the experiments were carried out in triplicate.

\section{Statistical analysis}

Student's t-test was used to calculate statistical significance. A p-value less than 0.05 was considered statistically significant (SPSS version 13). 
http://wjst.wu.ac.th

\section{Results and discussion}

$N R F 2$ and $K L F 1$ gene silencing by miR-144 represses $\gamma$-globin, a-globin and $\zeta$-globin gene expression in $\mathrm{K562}$ cell line

To test the functional effect of miR-144 for regulating NRF2 and KLF1 target mRNA to control globin gene, the gain evidence of miR-144 was investigated. After K562 cells were transfected with miR144 mimic, the expression of miR-144 increased compared to that of the untreated and negative control ( $p$ $<0.01$ ) (Figure 1). It was observed that 8.4-fold and 2.8-fold decreased in NRF2 and KLF1 target mRNA levels after miR-144 overexpression $(p<0.05)$, respectively (Figure 1). The upregulation of miR-144 was associated with $\boldsymbol{\gamma}$-globin, a-globin and $\zeta$-globin gene silencing by 3.3-fold, 2.7-fold, and 2.5-fold, respectively but had not effect to $\beta$-globin gene expression (Figure 2).
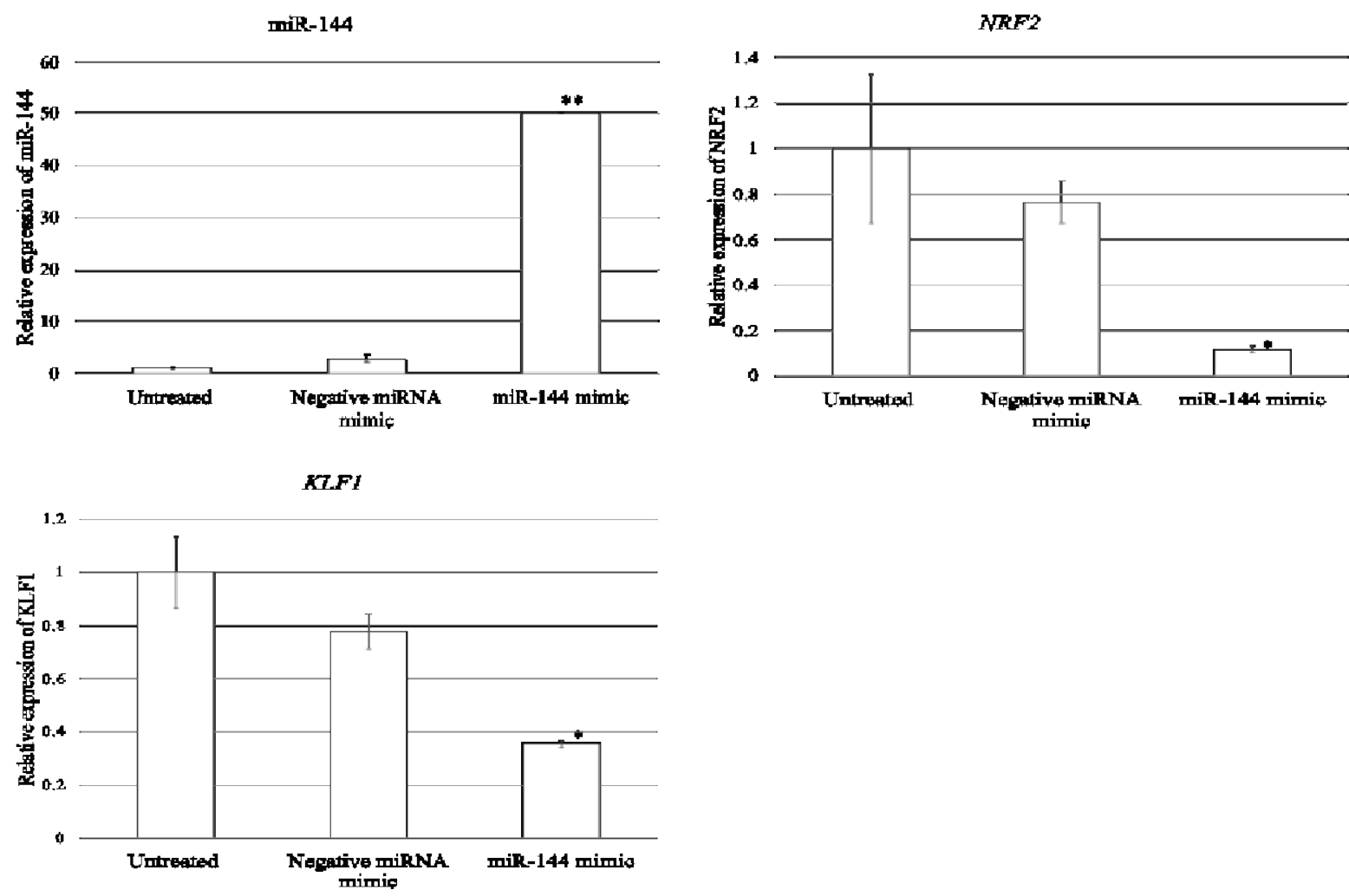

Figure 1 Overexpression of miR-144 regulated mRNA target in erythroblastic cell line. K562 cells were treated with hsa-miR-144 miRNA mimic and negative control. Expression of miR-144 and NRF2, KLF1 target gene expression was examined by qRT-PCR. Data are means of triplicate determinations.; *p $<$ $0.05, * * p<0.01$. 

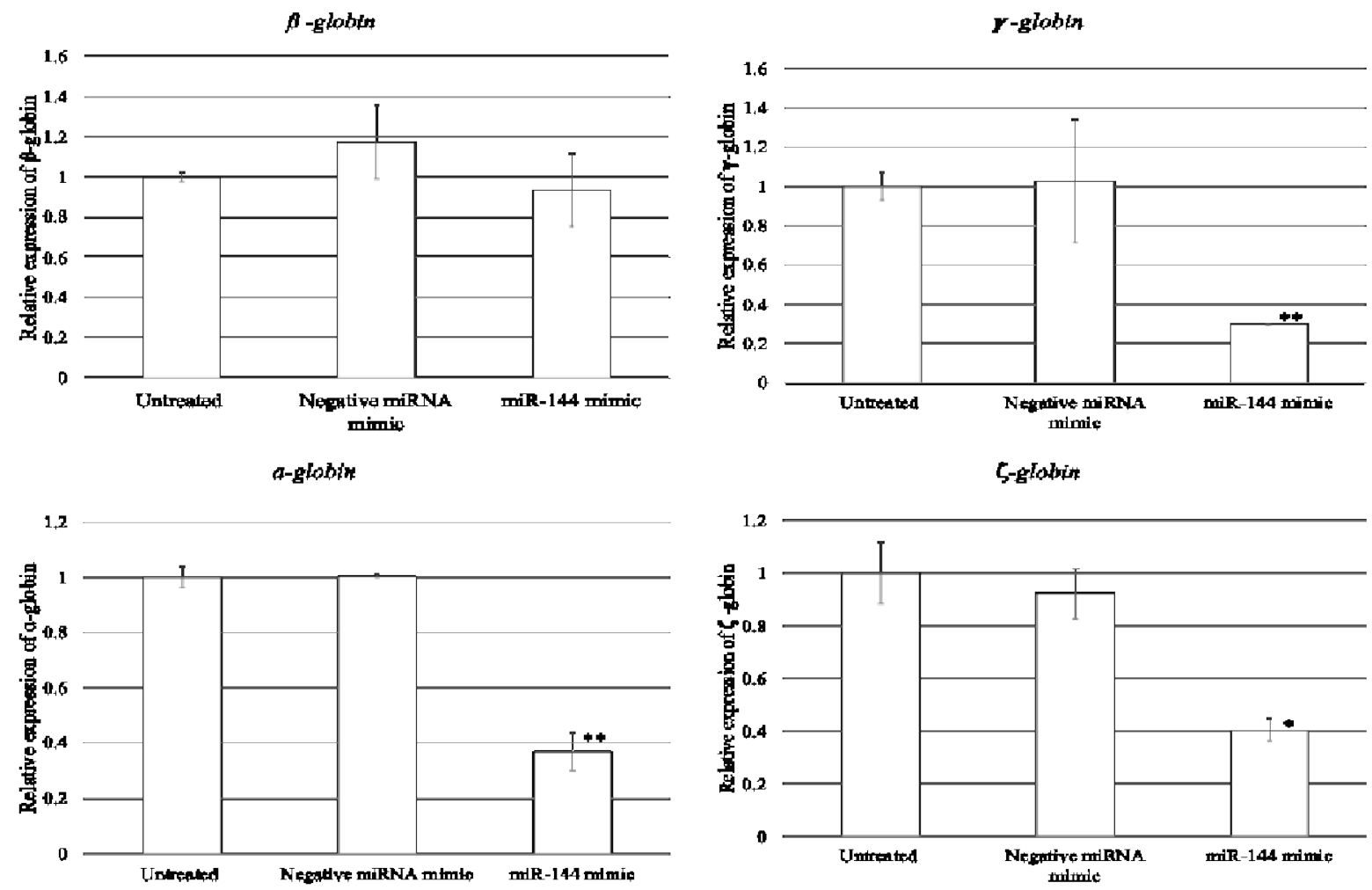

Figure 2 Overexpression of miR-144 regulated mRNA target involving in hemoglobin synthesis. K562 cells were treated with hsa-miR-144 miRNA mimic and negative control. Expression of $\beta$-globin, $\boldsymbol{\gamma}$ globin, a-globin and $\zeta$-globin gene expression was examined by qRT-PCR. Data are means of triplicate determinations.; $* p<0.05, * * p<0.01$.

The transfection of miR-144 inhibitor increases NRF2 and KLF1 gene expression and promoted $\gamma$-globin, a-globin and $\zeta$-globin gene expression in $\mathrm{K562}$ cell line

Conversely, inhibition of miR-144 expression by anti-miR-144 inhibitor produced 3.7-fold and 1.3fold increase in NRF2 and KLF1 target mRNA levels $(p<0.05)$ compared that of untreated cell (Figure 3). Moreover, anti-miR-144 inhibitor promotes an increase in $\boldsymbol{\gamma}$-globin, a-globin and $\boldsymbol{\zeta}$-globin gene transcription by 1.7-fold, 2.1-fold and 6.0-fold, respectively (figure 4). Anti-miR-144 inhibitor had no effect on $\beta$-globin gene expression (Figure 4a). 
miR-144

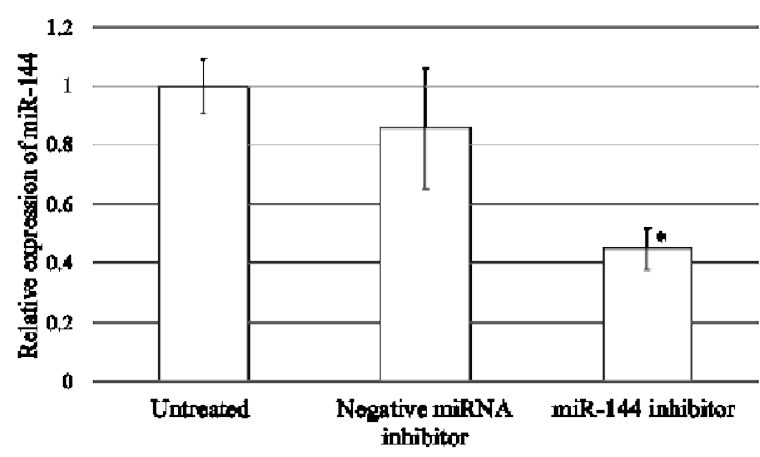

KLFI

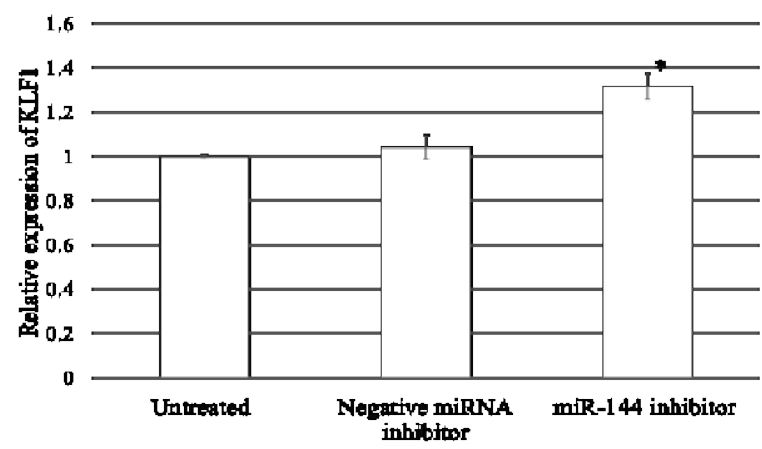

$N R F 2$

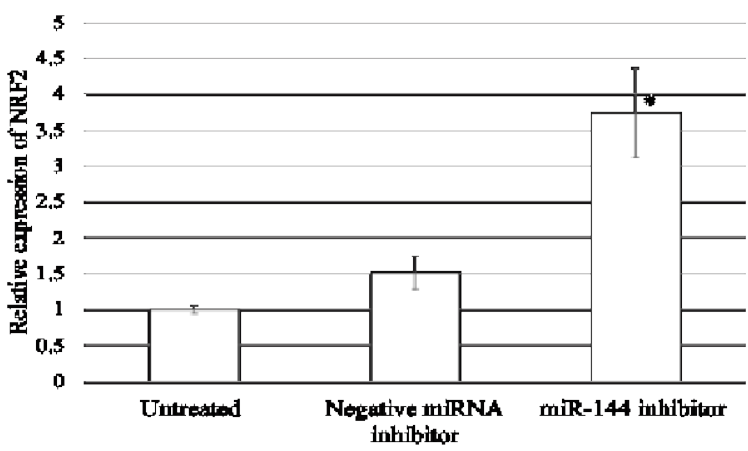

Figure 3 Loss of miR-144 expression in erythroblastic cell line. K562 cells were treated with hsa-miR144 miRNA inhibitor and negative control. Expression levels of miR-144 and NRF2, KLF1 target gene were examined by qRT-PCR. Data are means of triplicate determinations; ${ }^{*} p<0.05, * * p<0.01$.

This study identified that miR-144 was involved in $\boldsymbol{\gamma}$-globin, a-globin and $\zeta$-globin gene expression. The functional study in K562 cell line confirmed the ability of miR-144 in the regulation of $\boldsymbol{\gamma}$-globin gene expression through $N R F 2$. Likewise, in the loss of function, miR-144 inhibitor produced a fold change of NRF2 gene and increased $\boldsymbol{\gamma}$-globin. The result of this study is similar to that of $\mathrm{Li}, \mathrm{B}$ et al. who investigated in normal and sickle erythroid progenitor cells. They observed the regulation of miR-144 to NRF2 and $\boldsymbol{\gamma}$-globin at both mRNA and protein levels. They demonstrated a $30-50 \%$ decrease in NRF2 mRNA levels after miR-144 overexpression. Conversely, inhibition of miR-144 by inhibitor alone produced a 1.4-fold increase in NRF2 gene expression. Chromatin immunoprecipitation confirmed the binding of NRF2 to the $\gamma$-globin antioxidant response element, which was inhibited by miR-144 mimic treatment [10]. These data suggest that miR-144 may directly regulate NRF2 expression. However, chromatin immunoprecipitation or luciferase reporter assays are required for confirming the binding of miR-144 and NRF2 gene. The function of miR-144 has no effects on $\beta$-globin gene expression. However, in the gain of miR-144 function, the reduction of NRF2 gene and $\boldsymbol{\gamma}$-globin in K562 cell line seems to be higher than in erythroid progenitor cells. As a result, types of cell transfection, productivity, or efficiency of miRNA mimic generation, cannot be excluded. Besides $N R F 2$, previous report had demonstrated that BCL11A was a repressor of $\gamma$-globin expression during hemoglobin switching $[7,8,19]$.

The finding of this study is the first report on the effect of miR-144 inactivation or overexpression to adult a-globin and embryonic $\zeta$-globin gene expression through $K L F 1$ - the suspected target mRNA. Evidently, chromatin immunoprecipitation or luciferase reporter assays are required for confirming the

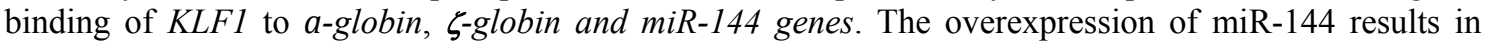


http://wjst.wu.ac.th

decreased a-globin gene expression and that correlates with $K L F 1$ silencing. This result was consistent with $K L F 1$ mutation in $\mathrm{a}^{0}$-thalassemia carriers. Red blood cell indices of these patients presented the significantly lower mean corpuscular volume (MCV) and mean corpuscular hemoglobin (MCH) [20]. Previous study showed that miR-144 regulated klfd signaling in embryonic a-globin regulation, but not $\beta$ globin expression in zebrafish embryo. The klfd selectively binds to the CACCC boxes in the promoters of both $\alpha$-globin and miR-144 genes to activate their transcriptions and thus lead to a negative feedback circuit to regulate the expression of embryonic $\alpha$-globin gene [18]. Zebrafish klfd conserved elements are similar to human and mouse KLF1 [21]. This transcription factor expresses within both embryonic and definitive erythropoiesis. The embryonic KLF1-/- mouse showed lower $\zeta$-globin gene expression than wild type [22].
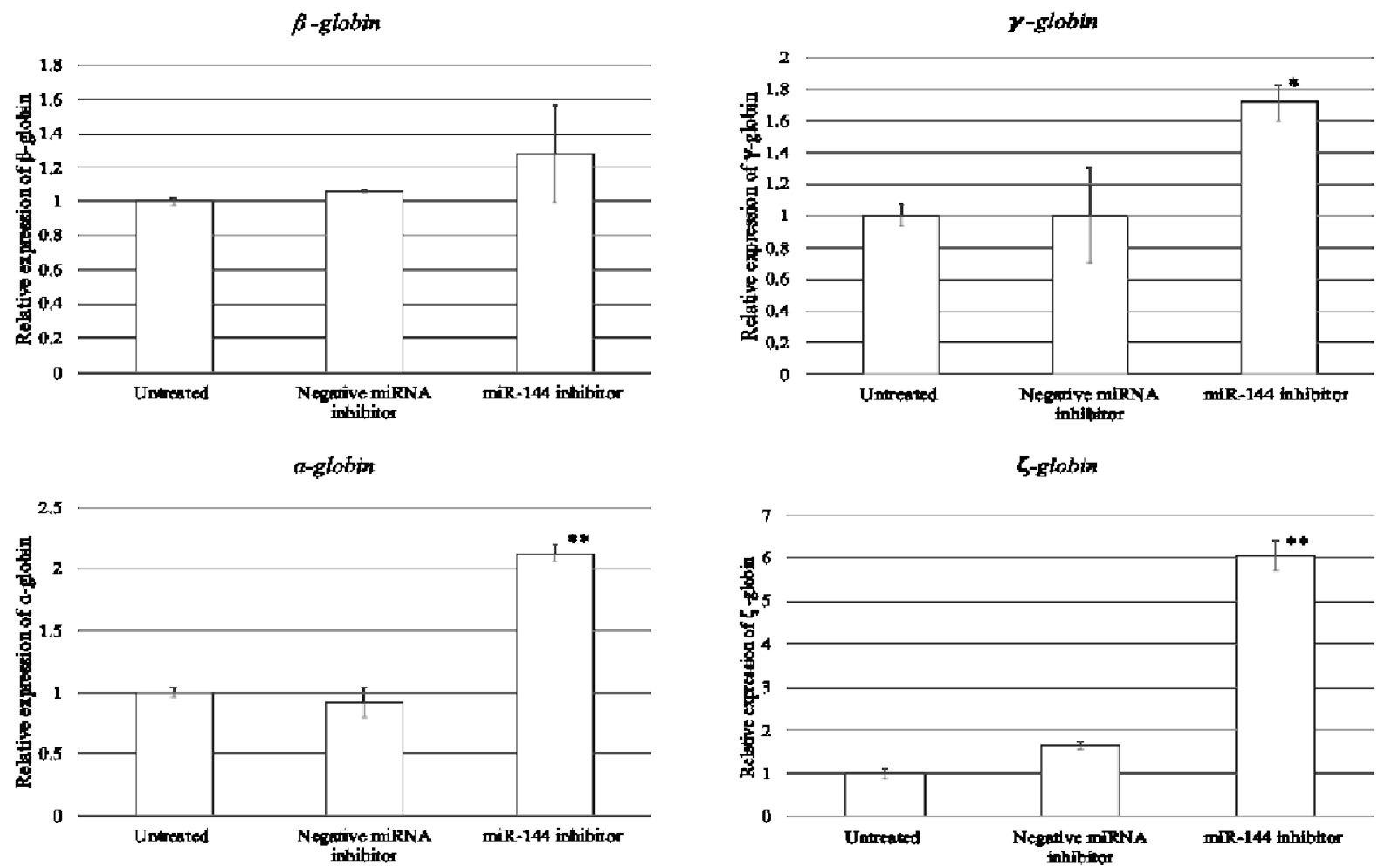

Figure 4 Loss of miR-144 regulated mRNA target involving in hemoglobin synthesis. K562 cells were treated with hsa-miR-144 miRNA mimic and negative control. Expression levels of $\beta$-globin, $\boldsymbol{\gamma}$-globin, $a$ globin and $\zeta$-globin gene were examined by qRT-PCR. Data are means of triplicate determinations.; $* p<$ $0.05, * * p<0.01$.

\section{Conclusions}

The regulation of globin gene synthesis is considerably essential to understand the principle controlling globin gene expression and the pathogenesis of hemoglobinopathy disease. The present study has demonstrated the functional studies of miR-144 in human erythroid cell line. The findings illustrate the role of miR-144 in the regulation of hemoglobin expression, especially $\boldsymbol{\gamma}$-globin, a-globin, and $\boldsymbol{\zeta}$ globin gene expression through target mRNAs, $N R F 2$ and $K L F 1$, respectively. These new insights may 
http://wjst.wu.ac.th

potentially provide new therapeutic opportunities for treating thalassemia by developing miRNA as a therapeutic agent to reduce excess a-globin or induce $\mathrm{Hb} F$ production in the future.

\section{Acknowledgements}

This work was supported by the budget revenue of Faculty of Medical Technology (MET601521S) Prince of Songkhla University, Thailand. We thank the Department of Pathology, Faculty of Medicine; and Thalassemia Research Center, Institute of Molecular Biosciences, Mahidol University, Thailand.

\section{References}

[1] DR Higgs, MA Vickers, AO Wilkie, IM Pretorius, AP Jarman, DJ Weatherall. A review of the molecular genetics of the human alpha-globin gene cluster. Blood 1989; 73, 1081-104.

[2] T Maniatis, EF Fritsch, J Lauer and RM Lawn. The molecular genetics of human hemoglobins. Annu. Rev. Genet. 1980; 14, 145-78.

[3] G Stamatoyannopoulos. Control of globin gene expression during development and erythroid differentiation. Exp. Hematol. 2005; 33, 259-71.

[4] DR Higgs, D Garrick, E Anguita, MD Gobbi, J Hughes, M Muers, D Vernimmen, K Lower, M Law, A Argentaro, MA Deville and R Gibbons. Understanding alpha-globin gene regulation: Aiming to improve the management of thalassemia. Ann. N. Y. Acad. Sci. 2005; 1054, 92-102.

[5] D Zhou, K Liu, CW Sun, KM Pawlik and TM Townes. KLF1 regulates BCL11A expression and gamma- to beta-globin gene switching. Nat. Genet. 2010; 42, 742-4.

[6] D Donze, TM Townes and JJ Bieker. Role of erythroid Kruppel-like factor in human gamma- to beta-globin gene switching. J. Biol. Chem. 1995; 270, 1955-9.

[7] J Xu, VG Sankaran, M Ni, TF Menne, RV Puram, W Kim and SH Orkin. Transcriptional silencing of \{gamma\}-globin by BCL11A involves long-range interactions and cooperation with SOX6. Genes Dev. 2010; 24, 783-98.

[8] J Xu, DE Bauer, MA Kerenyi, TD Vo, S Hou, YJ Hsu, H Yao, JJ Trowbridge, G Mandel and SH Orkin. Corepressor-dependent silencing of fetal hemoglobin expression by BCL11A. Proc. Natl. Acad. Sci. USA 2013; 110, 6518-23.

[9] M Roosjen, B McColl, B Kao, LJ Gearing, ME Blewitt and J Vadolas. Transcriptional regulators Myb and BCL11A interplay with DNA methyltransferase 1 in developmental silencing of embryonic and fetal beta-like globin genes. FASEB J. 2014; 28, 1610-20.

[10] B Li, X Zhu, CM Ward, A Starlard-Davenport, M Takezaki, A Berry, A Ward, C Wilder, C Neunert, A Kutlar and BS Pace. MIR-144-mediated NRF2 gene silencing inhibits fetal hemoglobin expression in sickle cell disease. Exp. Hematol. 2019; 70, 85-96.

[11] DP Bartel. MicroRNAs: Genomics, biogenesis, mechanism, and function. Cell 2004; 116, 281-97.

[12] I Azzouzi, H Moest, J Winkler, JC Fauchère, AP Gerber, B Wollscheid, M Stoffel, M Schmugge and O Speer. MicroRNA-96 directly inhibits gamma-globin expression in human erythropoiesis. PLoS One 2011; 6, e22838.

[13] YT Lee, JF de Vasconcellos, J Yuan, C Byrnes, SJ Noh, ER Meier, KS Kim, A Rabel, M Kaushal, SA Muljo and JL Miller. LIN28B-mediated expression of fetal hemoglobin and production of fetallike erythrocytes from adult human erythroblasts ex vivo. Blood 2013; 122, 1034-41.

[14] VG Sankaran, TF Menne, D Scepanovic, JA Vergilio, P Ji, J Kim, P Thiru, SH Orkin, ES Lander and HF Lodish. MicroRNA-15a and -16-1 act via MYB to elevate fetal hemoglobin expression in human trisomy 13. Proc. Natl. Acad. Sci. USA 2011; 108, 1519-24.

[15] V Lulli, P Romania, O Morsilli, P Cianciulli, M Gabbianelli, U Testa, A Giuliani and G Marziali. MicroRNA-486-3p regulates gamma-globin expression in human erythroid cells by directly modulating BCL11A. PLoS One 2013; 8, e60436.

[16] CM Ward, B Li and BS Pace. Stable expression of miR-34a mediates fetal hemoglobin induction in K562 cells. Exp. Biol. Med. (Maywood) 2016; 241, 719-29. 
http://wjst.wu.ac.th

[17] Y Li, D Liu, X Zhang, Z Li, Y Ye, Q Liu, J Shen, Z Chen, H Huang, Y Liang, X Han, J Liu, X Ang, $\mathrm{N}$ Mohandas and $\mathrm{X} \mathrm{Xu}$. miR-326 regulates HbF synthesis by targeting EKLF in human erythroid cells. Exp. Hematol. 2018; 63, 33-40.

[18] YF Fu, TT Du, M Dong, KY Zhu, CB Jing, Y Zhang, L Wang, HB Fan, Y Chen, Y Jin, GP Yue, SJ Chen, Z Chen, QH Huang, Q Jing, M Deng and TX Liu. Mir-144 selectively regulates embryonic alpha-hemoglobin synthesis during primitive erythropoiesis. Blood 2009; 113, 1340-9.

[19] J Xu, C Peng, VG Sankaran, Z Shao, EB Esrick, BG Chong, GC Ippolito, Y Fujiwara, BL Ebert, PW Tucker and SH Orkin. Correction of sickle cell disease in adult mice by interference with fetal hemoglobin silencing. Science 2011; 334, 993-6.

[20] F Jiang, YX Qu, GL Chen, J Li, JY Zhou, LD Zuo, C Liao and DZ Li. KFL1 gene variants in alphathalassemia individuals with increased fetal hemoglobin in a Chinese population. Hemoglobin 2018; 42, 161-5.

[21] AC Oates, SJ Pratt, B Vail, Y Yl, RK Ho, SL Johnson, JH Postlethwait and LI Zon. The zebrafish klf gene family. Blood 2001; 98, 1792-801.

[22] P Basu, TK Lung, W Lemsaddek, TG Sargent, DCJ Williams, M Basu, LC Redmond, JB Lingrel, JL Haar and JA Lloyd. EKLF and KLF2 have compensatory roles in embryonic beta-globin gene expression and primitive erythropoiesis. Blood 2007; 110: 3417-25. 